\title{
Exercise directly enhances myocardial tolerance to ischaemia-reperfusion injury in the rat through a protein kinase $\mathrm{C}$ mediated mechanism
}

\author{
N Yamashita, G F Baxter, D M Yellon
}

\begin{abstract}
Objective-To determine whether exercise is capable of protecting the myocardium from experimental infarction and to explore the involvement of protein kinase $\mathrm{C}$, a key signalling protein, in the development of any protection observed.

Methods-Rats were exercised on a treadmill for 30 minutes at 23-27 m/min. Sham treated animals were placed on the stationary treadmill but not exercised. Twenty four hours later, hearts were Langendorff perfused and subjected to 35 minute left main coronary artery occlusion followed by 120 minute reperfusion. Infarct size was determined by tetrazolium staining and expressed as a percentage of the risk zone $(\mathrm{I} / \mathrm{R} \%)$. To examine the potential signalling pathway, animals were treated with either the selective protein kinase $\mathrm{C}$ inhibitor chelerythrine, $5 \mathrm{mg} / \mathrm{kg}$ intraperitoneally, or with vehicle 10 minutes before the exercise or sham treadmill period.

Results-In the non-exercised group, mean (SEM) I/R was 48.4 (3.0)\%. In the exercised group, infarct size was reduced to $17.3(3.0) \%(\mathrm{p}<0.01)$. Infarct size limitation induced by exercise was abolished by chelerythrine (I/R 45.0 (6.0)\%). Chelerythrine pretreatment alone did not have any effect on infarct size (I/R 51.1 (3.9)\%). Differences in infarct size were independent of risk zone size and myocardial contractile function during ischaemia-reperfusion.

Conclusions-Experimental moderate exercise induces protection against myocardial infarction 24 hours later. Protein kinase C activation during exercise appears to be an important signal mediator of this protective response.

(Heart 2001;85:331-336)
\end{abstract}

Keywords: exercise; myocardial infarction; cardioprotection; protein kinase C

Epidemiological evidence suggests that regular physical exercise is associated with a reduced incidence of coronary artery disease. Well designed clinical investigations have shown that exercise is an independent cardioprotective factor, even in the presence of other risk factors. ${ }^{1-3}$ Although exercise can improve other known risk factors for coronary disease such as raised plasma lipid concentrations, obesity, and glucose intolerance, the underlying physiological mechanisms whereby exercise may reduce cardiovascular risk are complex and not well understood. One possible mechanism may be related to cellular and molecular adaptation induced by exercise. It is known that exercise increases catecholamine concentrations in plasma ${ }^{4}$ and heart tissue, ${ }^{5}$ increases body temperature, ${ }^{6}$ and may also induce tissue hypoxia/ ischaemia. Transient exposure of the myocardium to catecholamines, hyperthermia, or brief episodes of ischaemia-reperfusion is known to induce cardioprotection in various intact animal models in vivo and in isolated cardiac myocytes in vitro (for a review, see Baxter and Yellon ${ }^{6}$. However, up to now few studies have shown that exercise is directly cardioprotective. $^{7-10}$

Several groups have reported that previous sublethal ischaemia of the myocardium ${ }^{11-15}$ and whole body hyperthermia ${ }^{16-19}$ induce delayed myocardial protection - that is, enhanced resilience to infarction 24 hours later. The signal transduction pathways responsible for these delayed "preconditioning" responses are largely unknown. Recent data obtained in rabbit and rat hearts suggest the involvement of the early activation of one or more protein kinase $\mathrm{C}$ isoforms in delayed cardioprotection induced not only by ischaemic preconditioning $^{141520}$ but also by hyperthermia. ${ }^{19}$ We hypothesised that exercise causes myocardial protein kinase C activation which is an essential signalling step in the induction of protection. We tested this hypothesis using a rat model of standardised treadmill exercise with subsequent myocardial infarction ex vivo.

\section{Methods}

MATERIALS

Chelerythrine chloride was obtained from Sigma (Poole, Dorset, UK); zinc cadmium sulfide microspheres $1-10 \mu \mathrm{m}$ were from Duke Scientific (Palo Alto, California, USA); 2,3,5triphenyltetrazolium chloride was from Sigma. All other reagents were of analytical reagent quality.

\section{ANIMALS}

The care and use of animals in this work were in accordance with UK Home Office guidelines on the Animals (Scientific Procedures) Act 1986 (HMSO, London, UK). Male Sprague-Dawley rats (330-390 g) were obtained from Harlan (Bicester, Oxfordshire, UK). They were fed a standard pelleted chow (SDS, Witham, Essex, UK) and had free access to food and water at all times. 


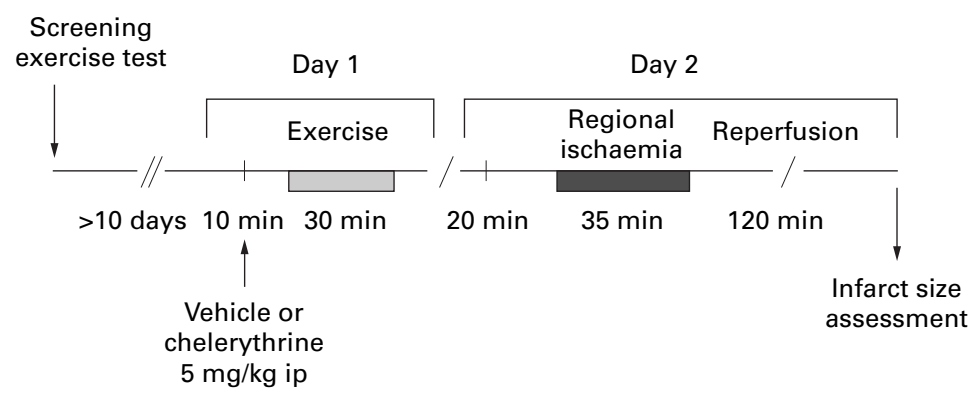

Figure 1 Experimental protocol. Rats were screened before the experiment for their ability to run on a treadmill. At least 10 days after screening, those animals that were able to run for 30 minutes were randomly assigned to either treadmill exercise or a corresponding sham period (day 1). Twenty four hours later (day 2), hearts were isolated and Langendorff. perfused. They were subjected to 35 minutes of coronary artery occlusion and reperfusion, after which the infarct size was assessed. ip, intraperitoneally.

EXERCISE PROTOCOL

A motor driven treadmill for small animals (Natsume Co, Tokyo, Japan) was used for standardised exercise protocols. Rats were initially subjected to a screening exercise test that determined if they could run on a motor driven treadmill at $20-25 \mathrm{~m} / \mathrm{min}, 0 \%$ gradient, for 20 minutes. Exercise began and ended with five minute "warm up" and "cool down" periods at $15 \mathrm{~m} / \mathrm{min}$ and $0 \%$ gradient; the duration of exercise included the warm up and cool down periods. Animals that could not complete this screening test were excluded from further study. At least 10 days after screening, rats were randomly assigned to four experimental groups:

- group 1-a group that received exercise pretreated with water for injection $(1 \mathrm{ml})$ as a vehicle (exercise group);

- group 2-a group that did not exercise and was placed on the immobilised treadmill for 30 minutes (control treadmill period) pretreated with water for injection $(1 \mathrm{ml}$ ) (sham treated group);

- group 3-a group that received exercise pretreated with chelerythrine chloride $5 \mathrm{mg} / \mathrm{kg}$ intraperitoneally, dissolved in water for injection, 10 minutes before exercise (exercise + chelerythrine group);

- group 4-a group that did not exercise and was placed on the immobilised treadmill for 30 minutes (control treadmill period) pretreated with chelerythrine chloride (sham + chelerythrine group).

The actual exercise protocol consisted of running on a treadmill at $23-27 \mathrm{~m} / \mathrm{min}, 0 \%$ gradient, for 30 minutes including the warm up and cool down periods, as described above for the screening test. Animals in the sham groups (groups 2 and 4) pursued normal exploratory behaviour or settled on the immobilised treadmill. In the exercised groups, the animals stopped running as soon as the treadmill was immobilised.

LANGENDORFF PERFUSION AND INFARCTION PROTOCOL

Twenty four hours after exercise, rats were heparinised $(1000 \mathrm{U} / \mathrm{kg})$ and deeply anaesthetised with $60 \mathrm{mg} / \mathrm{kg}$ sodium pentobarbitone (pentobarbital), given intraperitoneally. The heart was rapidly excised and perfused retrogradely by the Langendorff technique at constant pressure $\left(102 \mathrm{~cm} \mathrm{H}_{2} 0\right)$ with Krebs-
Henseleit buffer of the following composition (mmol/l): $\mathrm{NaCl} 118, \mathrm{KCl} 4.7, \mathrm{KH}_{2} \mathrm{PO} 41.2$, $\mathrm{MgSO}_{4} 1.2, \mathrm{NaHCO}_{3}$ 25.2, and glucose 11.0. ( $\mathrm{pH} 7.35-7.55$ when equilibrated with 95\% $\left.\mathrm{O}_{2} / 5 \% \quad \mathrm{CO}_{2}\right)$. A water filled latex balloon, coupled to a pressure transducer (Statham type P23XL, Gould Instruments, Ilford, UK), was inserted into the left ventricular cavity through the left atrium for pressure recordings. The balloon was inflated with water to give a left ventricular end diastolic pressure of between $8-12 \mathrm{~mm} \mathrm{Hg}$, and the same volume was maintained throughout the experiment. Myocardial temperature was monitored continuously with a thermoprobe inserted into the right ventricle. The hearts were surrounded by a water jacketed chamber to maintain temperature close to $37^{\circ} \mathrm{C}$.

For temporary occlusion of the left coronary artery, a 3-0 silk suture was placed around the artery a few millimetres distal to the aortic root. After 20 minutes of stabilisation, regional ischaemia was induced by tightening the snare around the left coronary artery for 35 minutes. The suture was threaded through a $10 \mathrm{~mm}$ polypropylene tube to form a snare, which was clamped onto the epicardial surface with a haemostat forceps. Thereafter, the heart was reperfused for 120 minutes. Coronary flow was measured throughout the ischaemiareperfusion procedure by timed collection of the effluent. Heart rate and left ventricular developed pressure (the difference between left ventricular systolic and end diastolic pressures) were continuously recorded ("Windograf" recorder, Gould Instruments). Rate-pressure product was calculated as the product of heart rate and left ventricular developed pressure. At the end of the reperfusion period, the coronary artery ligature was retied and a $5 \mathrm{mg} / \mathrm{ml}$ suspension of zinc-cadmium sulfide fluorescent microspheres (in $0.9 \% \mathrm{wt} / \mathrm{vol}$ saline) was slowly infused through the aorta to delineate the myocardial risk zone under ultraviolet light.

After removal of the right ventricle and atria, the heart was frozen at $-20^{\circ} \mathrm{C}$ for one hour, and then sectioned into $2 \mathrm{~mm}$ transverse sections from apex to base (six to seven slices per heart). Following defrosting, the slices were incubated at $37^{\circ} \mathrm{C}$ with $1 \%$ wt/vol triphenyltetrazolium chloride (TTC) in phosphate buffer ( $\mathrm{pH}$ 7.4) for 10-20 minutes and fixed in $10 \% \mathrm{vol} / \mathrm{vol}$ formaldehyde solution to distinguish clearly stained viable tissue and unstained necrotic tissue. ${ }^{21}$ The left ventricular infarct zone was determined using computed planimetry (Summa Sketch II; Summa Graphics, Seymour, Connecticut, USA) and expressed as a percentage of the risk zone.

The experimental protocol is summarised in fig 1 .

STATISTICAL ANALYSIS

All data are presented as mean (SEM). Comparisons in coronary flow, heart rate, left ventricular developed pressure, and ratepressure product were determined by repeated measures analysis of variance (ANOVA). Differences in infarct size between groups were analysed by one way ANOVA followed by 
Table 1 Haemodynamic performance during ischaemia-reperfusion protocol

\begin{tabular}{lcclll}
\hline Group & $\begin{array}{l}\text { Stabilisation } \\
\text { period }\end{array}$ & $\begin{array}{l}5 \text { min } \\
\text { ischaemia }\end{array}$ & $\begin{array}{l}30 \text { min } \\
\text { ischaemia }\end{array}$ & $\begin{array}{l}5 \text { min } \\
\text { reperfusion }\end{array}$ & $\begin{array}{l}\text { 120 min } \\
\text { reperfusion }\end{array}$ \\
\hline $\begin{array}{l}\text { Heart rate (beats/min) } \\
\text { Sham + V }\end{array}$ & $283(6)$ & $281(11)$ & $276(15)$ & $281(15)$ & $281(12)$ \\
Sham + Che & $290(11)$ & $272(17)$ & $270(16)$ & $268(26)$ & $286(17)$ \\
Ex + V & $298(9)$ & $286(8)$ & $301(9)$ & $286(13)$ & $254(31)$ \\
Ex + Che & $276(4)$ & $264(10)$ & $276(11)$ & $267(8)$ & $264(6)$ \\
Left ventricular developed pressure (mm $\mathrm{Hg})$ & & & \\
Sham + V & $119(8)$ & $66(9)$ & $85(7)$ & $86(8)$ & $81(8)$ \\
Sham + Che & $120(6)$ & $55(4)$ & $75(5)$ & $99(7)$ & $88(4)$ \\
Ex + V & $105(4)$ & $58(7)$ & $73(6)$ & $91(6)$ & $82(5)$ \\
Ex + Che & $101(8)$ & $47(4)$ & $73(3)$ & $104(6)$ & $80(4)$ \\
Rate-pressure product $($ mm Hg/min $\times 1000)$ & & & \\
Sham + V & $33.9(2.8)$ & $18.9(2.9)$ & $23.5(2.3)$ & $24.9(3.3)$ & $23.1(2.7)$ \\
Sham + Che & $31.9(2.6)$ & $14.6(1.1)$ & $20.7(1.5)$ & $25.5(2.4)$ & $24.9(1.5)$ \\
Ex + V & $31.4(1.7)$ & $16.4(1.9)$ & $22.0(1.9)$ & $25.9(2.0)$ & $21.3(3.1)$ \\
Ex + Che & $30.4(2.0)$ & $14.9(0.7)$ & $18.8(1.5)$ & $28.4(1.9)$ & $20.9(1.2)$ \\
\hline
\end{tabular}

Values are mean (SD).

$\mathrm{Ex}+\mathrm{Che}$, chelerythrine treated before exercise; $\mathrm{Ex}+\mathrm{V}$, vehicle treated before exercise; Sham + $\mathrm{Che}$, chelerythrine treated before sham procedure; Sham $+\mathrm{V}$, vehicle treated before sham procedure.

Fisher's protected least significant difference test. Significance was assumed at $\mathrm{p}<0.05$.

\section{Results}

EXCLUSION CRITERIA

Fifty two rats were assessed for their ability to run on the treadmill. Thirty of these animals were capable of running on the treadmill and were subsequently used in the study. During the infarction protocol, all hearts had coronary flow within $10-16 \mathrm{ml} / \mathrm{min}$ and left ventricular developed pressure of $>80 \mathrm{~mm} \mathrm{Hg}$ at the end of the stabilisation period, conforming with predetermined inclusion criteria. The efficiency of coronary occlusion was indicated by a coronary flow diminution of $>30 \%$. Two hearts developed ventricular fibrillation during coronary occlusion or the first minute of reperfusion (one sham + vehicle and one sham + chelerythrine). Both converted back to sinus rhythm spontaneously within two minutes and were not excluded. Two hearts were excluded because of non-conformity with these predetermined criteria, and thus we report data from 28 successfully completed experiments.

CARDIAC FUNCTION DATA

Table 1 summarises heart rate, left ventricular developed pressure, and rate-pressure product data recorded in the four groups at the end of stabilisation and during ischaemia-reperfusion. No differences in heart rate, left ventricular developed pressure, or rate-pressure product were observed between the groups. Changes in coronary flow during ischaemia-reperfusion are shown in fig 2. Coronary flow was similar in all groups during stabilisation, during ischaemia, and up to 90 minutes of reperfusion. However, at 120 minutes of reperfusion, the exercised group showed significantly better coronary flow than the control group without exercise. This beneficial effect induced by exercise was not seen in the exercise + chelerythrine treated group, although chelerythrine treatment alone did not have any effect on coronary flow.

INFARCT SIZE

Risk zone size and infarct data are presented in fig 3. There were no significant differences in area at risk expressed as a percentage of the

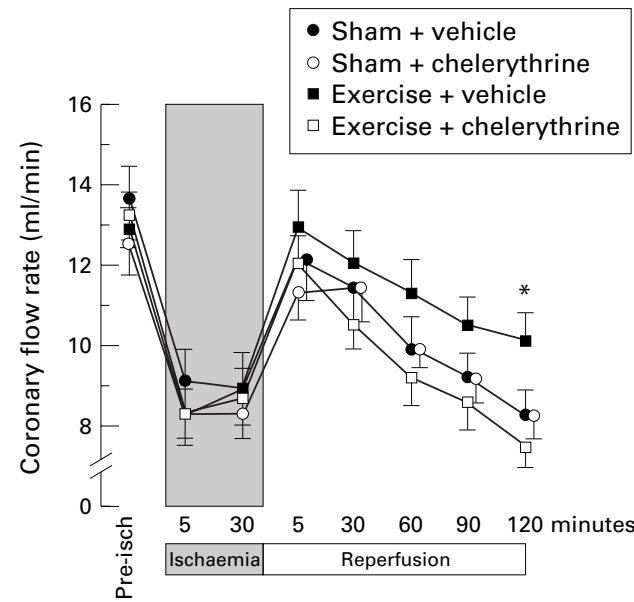

Figure 2 Changes in coronary flow during an in vitro (Langendorff perfusion) ischaemia-reperfusion protocol. Rats were treated with vehicle or chelerythrine chloride ( $5 \mathrm{mg} / \mathrm{kg}$ intraperitoneally) 10 minutes before exercise or sham treatment and 24 hours before ischaemia (see fig 1). ${ }^{\star} p<0.05 v$ sham + vehicle group $(n=7$ /group $)$.
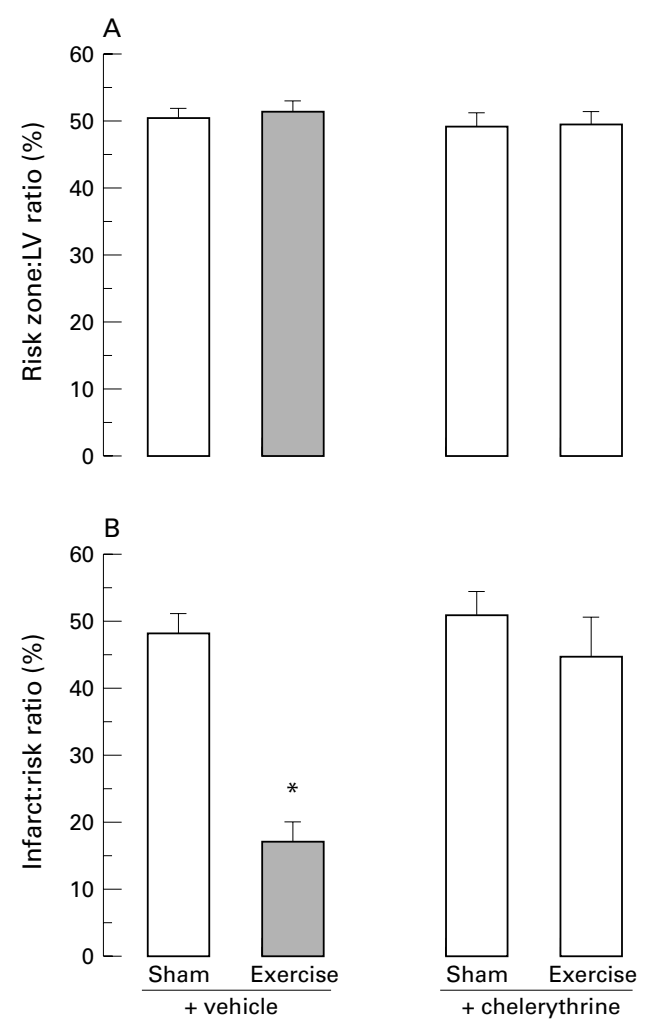

Figure 3 (A) Risk zone size expressed as percentage of total left ventricle muscle volume. (B) Infarct size expressed as percentage infarction of the risk zone in hearts subjected to 35 minutes of coronary occlusion followed by 120 minutes of reperfusion. Values are means, error bars $=S E M$. Rats were treated with vehicle or chelerythrine chloride $(5 \mathrm{mg} / \mathrm{kg}$ intraperitoneally) 10 minutes before exercise or sham treatment and 24 hours before ischaemia (see fig 1). ${ }^{\star} p<$ $0.01 v$ sham + vehicle group $(n=7 /$ group $)$.

whole left ventricle between the groups (fig 3A). In the exercise group, infarct size (fig 3B) was significantly reduced compared with the sham treated group without exercise (17.3 (3.0) $\%$ and 48.4 (3.0)\%, respectively). This infarct size reduction induced by exercise was abolished in the exercise + chelerythrine treated group $(45.0$ (6.0)\%). Chelerythrine chloride pretreatment did not have any effect 
on infarct size (51.1 (3.9)\%). These data indicate that exercise significantly reduced infarct size 24 hours later. Pretreatment with chelerythrine chloride, a selective protein kinase C inhibitor, abolished the beneficial effect on infarct size.

\section{Discussion}

Our findings may be summarised as follows. An episode of moderate physical exercise conferred a primary cardioprotective effect on the myocardium that resulted in limitation of infarct size 24 hours later. This effect was independent of any modifying actions on cardiac innervation, or circulating factors that might influence infarct size, as we studied responses to ischaemia-reperfusion in an isolated, blood free preparation. Pharmacological inhibition of protein kinase $\mathrm{C}$ activation during the exercise period resulted in abrogation of the protective response, suggesting that early activation of this enzyme is a key signalling intermediate in the development of the adaptive response.

The present study provides evidence that a single episode of moderate physical exercise serves as a physiological stimulus that has a directly beneficial effect on myocardial tolerance to ischaemia-reperfusion injury. This highly protective effect of exercise was manifested in a model of infarction that is independent of any modifying effects of circulating and systemic factors which might influence infarct size. These include neutrophil leucocytes and other inflammatory cell types. The effects of exercise on neutrophil function and activity are variable and poorly characterised but under some conditions neutrophil function may be enhanced by physical exercise. $^{22}$ In the present study any confounding effects of exercise on neutrophil function and other circulating inflammatory mediators during subsequent ischaemia and reperfusion were obviated. While tissue leucocytes may still be present in isolated heart preparations, it is not clear to what extent these may contribute to ischaemia-reperfusion injury or how they may be modified by exercise. The contribution of collateral vessel recruitment in the exercised group can largely be discounted as a mechanism of infarct size limitation, as the rat heart has a very sparse native coronary collateral circulation. ${ }^{23}$ Furthermore, while limited angiogenesis may be stimulated in rat heart by chronic exercise, ${ }^{24}$ there are no reports of detectable collateral vessels developing following a single episode of exercise.

In addition to limitation of infarct size, hearts from rats exercised 24 hours previously showed improved coronary flow characteristics at 120 minutes after reperfusion. As perfusion pressure was constant, this increased coronary flow represents a decreased coronary resistance after reperfusion in the exercise group. This supports a previous finding of a greater coronary flow response in exercise trained rat hearts on reperfusion. ${ }^{7}$ Kaeffer and colleagues have reported that ischaemic preconditioning induced delayed protection against reperfusion induced coronary endothelial injury. ${ }^{25}$ Exercise also induced endothelial constitutive nitric oxide synthase in a canine model. ${ }^{26}$ The production of $\mathrm{NO}$ during reperfusion might therefore contribute to an exercise induced beneficial effect of coronary flow after reperfusion, and additional work should be undertaken to assess this possibility.

Previous experimental reports using varying exercise protocols have shown consistent benefit against ischaemia-reperfusion injury. For example, exercise for five days a week over 11-16 weeks ${ }^{78}$ or three periods of exercise on three consecutive days ${ }^{9}$ resulted in a improved recovery of myocardial contractile function after ischaemia-reperfusion in the rat heart. Our present study showed that a single period of exercise provided delayed cardioprotection against ischaemia-reperfusion injury 24 hours later, with infarct size as the end point. In an earlier study, Locke and colleagues showed that a single exercise period did not induce cardioprotection 24 hours after exercise, using contractile recovery as the end point, ${ }^{9}$ while in a rat study, Yamashita and associates reported that running for 30 minutes at $27-30 \mathrm{~m} / \mathrm{min}$ provided protection against infarction 36-60 hours after exercise, but not at 24 hours. ${ }^{10}$ Thus differences in the time course of exercise induced cardioprotection may depend on the experimental conditions, including the severity of the previous exercise, animal strain, and the ischaemia-reperfusion conditions. Such variations are similar to those seen with hyperthermia induced cardioprotection, the extent and time course of which vary with the severity of the preceding hyperthermia and the severity of the ischaemia-reperfusion protocol. ${ }^{17}{ }^{19}$

The role of protein kinase $\mathrm{C}$ activation in the delayed cardioprotective effect of exercise is a novel finding. The involvement of this kinase in exercise induced adaptation may parallel its role in ischaemic preconditioning ${ }^{14}{ }^{15}$ or hyperthermia. ${ }^{18} 19$ In a rabbit model of coronary artery occlusion in vivo, the delayed protection following ischaemic preconditioning was abolished by chelerythrine. ${ }^{14}$ Conversely, direct protein kinase $\mathrm{C}$ activation in the rabbit with a synthetic analogue of diacylglycerol, the physiological activator of protein kinase C, invoked an adaptive mechanism leading to enhanced myocardial tolerance to ischaemia 24 hours later. ${ }^{27}$ In our present study, chelerythrine chloride, a protein kinase C inhibitor, completely abolished the exercise induced delayed cardioprotection, not only in myocardial infarct size but also in coronary flow after ischaemia-reperfusion injury. Although chelerythrine is regarded as a potent and specific inhibitor of protein kinase $\mathrm{C}$ activation in vitro, ${ }^{28}$ it may block other kinases when used in vivo. Therefore we cannot exclude the possibility that the alkaloid may have other nonspecific actions. The dose used in this study $(5 \mathrm{mg} / \mathrm{kg}$ ) was previously reported to inhibit delayed protection against myocardial infarction in the rabbit, ${ }^{14}$ and has recently been reported to inhibit the ischaemia induced translocation of protein kinase $\mathrm{C} \varepsilon$ and $\eta$ isoforms (PKC- $\varepsilon$, PKC- $\eta$ ) in rabbit myocardium..$^{20}$ In this study, we did not examine which isoforms of protein kinase $\mathrm{C}$ play a role in the 
exercise induced delayed cardioprotection. However, it has been reported that PKC- $\varepsilon$ participates in the development of delayed preconditioning against myocardial stunning and infarction in conscious rabbits, ${ }^{1520}$ and in the protection conferred by hypoxic preconditioning against hypoxia induced cell death in isolated rat cardiac myocytes. ${ }^{29}$

The possibility that myocardial hypoxia resulting from exercise acts as the primary trigger of adaptation cannot be discounted at this stage. Although heart rate increased notably during exercise, quantification of cardiovascular responses was impossible in the running animals. However, we believe that the exercise stimulus applied here is submaximal because in other rat exercise studies either a longer duration or a faster treadmill rate has been used. ${ }^{7-9}$ An interesting question that follows on from these findings relates to the nature of the proximal signals that activate protein kinase C. Several possible local or circulating mediators associated with moderate exercise can be postulated. These include endogenous ligands acting on 7-transmembrane G protein coupled receptors such as noradrenaline (norepinephrine), bradykinin, adenosine, and endogenous opioid peptides. All these mediators are known to be released in the myocardium under hypoxic conditions, with subsequent activation of protein kinase $\mathrm{C}$ and induction of delayed cardioprotection. ${ }^{6}$ In addition some of these mediators, such as noradrenaline and opioid peptides, may be released from intramyocardial neurones in response to exercise. Reactive oxygen species may activate protein kinase $\mathrm{C}$ independently of $\mathrm{G}$ proteins and could be generated during moderate exercise. $\delta$-Opioid receptor stimulation with synthetic analogues is known to protect rat myocardium against infarction 24-48 hours later ${ }^{30}$ and bolus dosing with noradrenaline has been shown to induce delayed cardioprotection in rat heart through an $\alpha_{1}$ adrenoreceptor mediated mechanism. ${ }^{31}$ As release of endogenous opioid peptides, particularly endorphins, is of special interest in relation to exercise, the participation of endorphins could be examined in subsequent studies. We did not determine the potential roles of these mediators but it may be pertinent to measure their plasma concentrations following exercise. Further studies could be designed to investigate the roles of such mediators by using pharmacological antagonists such as naloxone.

\section{CONCLUSIONS}

Exercise carried out 24 hours before ischaemia-reperfusion produced myocardial adaptation which resulted in delayed myocardial protection 24 hours later. Protein kinase C inhibition blocked this protection, suggesting that the early activation of this agent during exercise is a key signalling intermediate necessary for this endogenous response to occur. The distal molecular mechanisms whereby the early activation of protein kinase $\mathrm{C}$ during exercise protect the heart from ischaemiareperfusion injury are not yet known. We speculate that multiple downstream kinase cascades are activated distally to protein kinase C, with subsequent transcriptional regulation of as yet undetermined protein effectors that confer an ischaemia tolerant phenotype many hours after the physiological trigger of adaptation.

We acknowledge the financial support of the British Heart Foundation and an educational grant from Chugai Pharmaceutical Co (Japan). We are grateful to the Hatter Foundation and the Pentland Group for continuing support.

1 Fletcher GF, Balady G, Frolicher VF, et al. Exercise standards. A statement for healthcare professionals from the American Heart Association. Writing Group. Circulation 1995;91:580-615.

2 Fletcher GF, Blaire SN, Blumentahl J, et al. Statement on exercise. Benefits and recommendations for physical activity programs for all Americans. A statement for health proity programs for all Americans. A statement for health proessionals by the Committee on Exercise and Cardiac Rehabilitation of the Council on Clinical Cardiology, American Heart Association. Circulation 1992;86:340-4.

3 Bijnen FC, Caspersen C, Mosterd WL. Physical inactivity as a risk factor for coronary heart disease: a WHO and International Society and Federation of Cardiology position statement. Bull WHO 1994;72:1-4

4 Francis GS, Goldsmith SR, Ziesche SM, et al. Response of plasma norepinephrine to dynamic exercise in patients with congestive heart failure. Am f Cardiol 1982;49:1152-6.

5 Schomig A, Dart AM, Diets R, et al. Release of endogenous catecholamines in the ischemic myocardium of the rat. Circ Res 1984;55:689-701

6 Baxter GF, Yellon DM, eds. Delayed preconditioning and adaptive cardioprotection. Dordrecht: Kluwer Academic Publishers, 1998.

7 Bowles DK, Farra RP, Starnes JW. Exercise training improves cardiac function following ischemia in the isolated, working rat heart. Am F Physiol 1992;263:H804-9. Bowles DK, Starnes JW. Exercise training improves metabolic response after ischemia in isolated working rat heart. F Appl Physiol 1994;76:1608-14.

9 Locke M, Tanguay RM, Klabundei RE, et al. Enhanced postischemic myocardial recovery following exercise induction of HSP 72. Am ₹ Physiol 1995;269:H320-5.

10 Yamashita N, Hoshida S, Otsu K, et al. Exercise provides direct biphasic cardioprotection via manganese superoxide dismutase activation. $\mathcal{F}$ Exp Med 1999;189:1699-706.

11 Kuzuya T, Hoshia S, Yamashita N, et al. Delayed effects of sublethal ischemia on the acquisition of tolerance to ischemia. Circ Res 1993;72:1293-9.

12 Marber MS, Latchman DS, Walker JM, et al. Cardiac stress protein elevation 24 hours after brief ischemia or heat stress is associated with resistance to myocardial infarction. Circulation 1993;88:1264-72.

13 Baxter GF, Marber MS, Patel VC, et al. Adenosine receptor involvement in a delayed phase of protection 24 hours following ischemic preconditioning. Circulation 1994;90: 2993-3000.

14 Baxter GF, Goma FM, Yellon DM. Involvement of protein kinase $\mathrm{C}$ in the delayed cytoprotection following sublethal ischaemia in rabbit myocardium. Br f Pharmacol 1995;115: 1schaemia $22-4$.

15 Qiu Y, Ping P, Tang X-L, et al. Direct evidence that protein kinase C plays an essential role in the development of late preconditioning against myocardial stunning in conscious rabbits and that $\varepsilon$ is the isoform involved. $f$ Clin Invest 1998;101:2182-98.

6 Currie RW, Karmazyn M, Kloc M, et al. Heat-shock response is associated with enhanced postischemic ventricular recovery. Circ Res 1988 63:543-9.

17 Hutter MM, Sievers RE, Barbosa V, et al. Heat-shock protein induction in rat hearts: a direct correlation between the amount of heat-shock protein induced and the degree of myocardial protection. Circulation 1994;89:355-60.

18 Joyeux M, Baxter GF, Thomas DL, et al. Protein kinase C is involved in resistance to myocardial infarction induced by involved in resistance to myocardial infarction ind

19 Yamashita N, Hoshida S, Taniguchi N, et al. Whole-body hyperthermia provides biphasic cardioprotection against ischemia/reperfusion injury in the rat. Circulation 1998;98: 1414-21.

20 Ping $\mathrm{P}$, Zhang J, Qui Y, et al. Ischemic preconditioning induces selective translocation of protein kinase $\mathrm{C}$ isoforms $\varepsilon$ and $\eta$ in the hearts of conscious rabbits without subcelluar redistribution of total protein kinase C activity. Circ Res 1997;81:404-14.

21 Fishbein MC, Meerbaum S, Rit J, et al. Early phase acute myocardial infarct size quantification: validation of the triphenyltetrazolium chloride tissue enzyme staining technique. Am Heart F 1981;101:593-600.

22 Smith JA, Pyne DB. Exercise, training, and neutrophil function. Exerc Immunol Rev 1997;3:96-116.

23 Maxwell MP, Hearse DJ, Yellon DM. Species variation in the coronary collateral circulation during regional myocardial ischaemia: a critical determinant of the rate of evolution and extent of myocardial infarction. Cardiovasc Res 1987;21:737-46.

24 Koerner JE, Terjung RL. Effect of physical training on coronary collateral circulation of the rat. $\mathcal{F}$ Appl Physiol 1982; $52: 376-87$. 
25 Kaeffer N, Richard V, Thuillez C. Delayed coronary endothelial protection 24 hours after preconditioning. Role endothelial protection 24 hours after preconditio

26 Laughlin MH. Endothelium-mediated control of coronary vascular tone after chronic exercise training. Med Sci Sports Exerc 1995;27:1135-44

27 Baxter GF, Mocanu MM, Yellon DM. Attenuation of myocardial ischaemic injury $24 \mathrm{~h}$ after diacylglycerol treatment in vivo. 7 Mol Cell Cardiol 1997;29:1967-75.

28 Herbert JM, Augereau JM, Maffrand JP. Chelerythrine is a potent and specific inhibitor of protein kinase C. Biochem Biophys Res Commun 1990;172:993-9.
29 Gary MO, Karliner JS, Mochly-Rosen D. A selective $\varepsilon$-protein kinase $\mathrm{C}$ antagonist inhibits protection of cardiac myocytes from hypoxia-induced cell death. 7 Biol Chem 1997;272:30954-1.

30 Fryer RM, Hsu AK, Eells JT, et al. Opioid-induced second window of cardioprotection: potential role of mitochondrial KATP channels. Circ Res 1999;84:846-51.

31 Meng X, Shames BD, Pulido EJ, et al Adrenergic induction of bimodal myocardial protection: signal transduction and cardiac gene reprogramming. Am f Physiol 1999;276: R1525-33.

\section{IMAGES IN CARDIOLOGY}

\section{Asymptomatic diastolic compression of a coronary artery}

Coronary angiography was performed on a 67 year old woman before mitral valve replacement for endocarditis. Twenty one years previously she was operated on because of symptomatic mitral stenosis, when a closed mitral valvotomy was undertaken. The patient did not have symptoms of syncope, palpitations or other signs of myocardial ischaemia, but did have fever, asthenia, joint pain, malaise and evidence of mild heart failure. Blood cultures were positive for Staphylococcus epidermidis. A transthoracic and transoesophageal echocardiogram confirmed the diagnosis of mitral endocarditis.

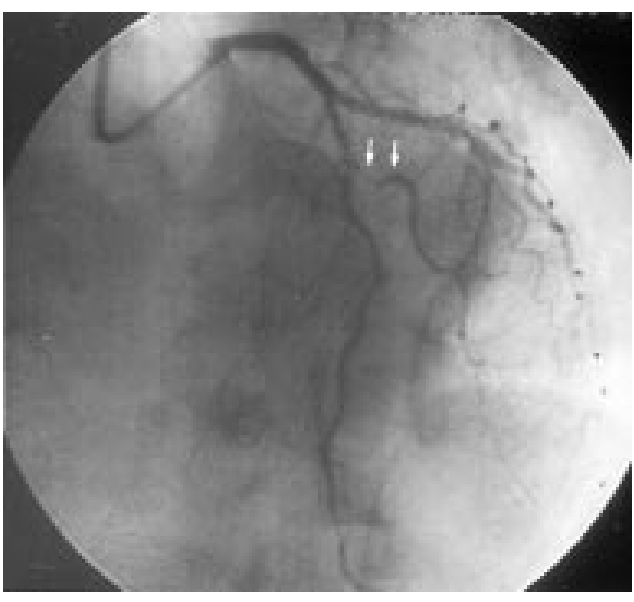

Coronary angiography showed normal coronary arteries and evidence of diastolic compression of the first diagonal branch (above and top right). Left ventriculography indicated that the diastolic compression was caused by expansion of the anterolateral segment of the left ventricle (bottom right).
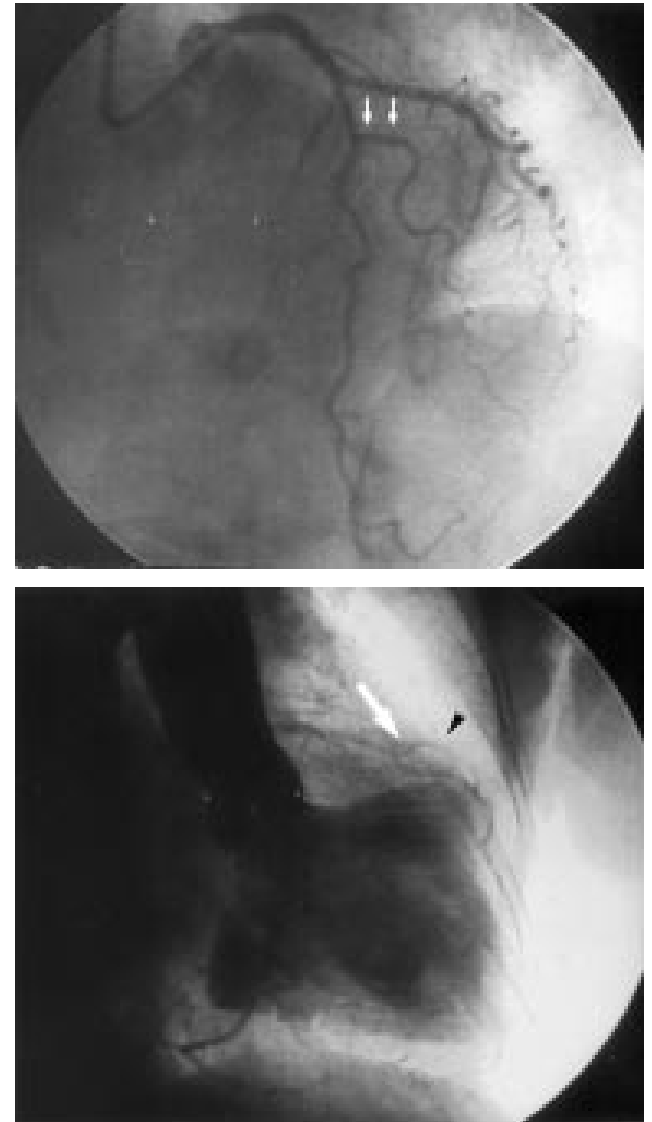

To our knowledge this is the first case of diastolic compression of a coronary artery reported in the English literature.

JORGE TOQUERO JUAN FRANCISCO OTEO MANUEL UGARTE jetr@alehop.com 